\title{
Agricultura familiar e mercados atacadistas: dinâmicas sociais da Central de Comercialização da Agricultura Familiar (Cecaf/Ceasa) em Recife - Pernambuco
}

\author{
Family farming and wholesale markets: Social dynamics \\ of the Central of Commercialization of Family farming \\ (Cecaf / Ceasa) in Recife - Pernambuco
}

\author{
Juliana Gomes Moraes ${ }^{1}$ (D) Maria Luiza Lins e Silva Pires ${ }^{1}$
}

\begin{abstract}
Resumo: Esta pesquisa analisa as dinâmicas sociais de funcionamento da Central de comercialização da agricultura familiar (Cecaf), no âmbito do Ceasa-PE, considerando a diversidade social, as bases associativas, as estratégias de comercialização e as disputas locais de uso do espaço. Como se configura a dinâmica cotidiana de comercialização na Cecaf e quem são os seus atores são algumas das questões que conduzem este trabalho. Esta pesquisa envolveu uma amostra de 38 entrevistados, entre agricultores comerciantes e gestores. Criada com o propósito de atender exclusivamente agricultores familiares beneficiários do Pronaf, a Cecaf precisou ampliar seu público-alvo, dada a escassez de usuários que atendesse a esse critério, favorecendo a instalação de uma diversidade de atores. Estas experiências de comercialização definem modos de vida e de trabalho alimentados por um aprendizado permanente sobre as estratégias de compra e venda dos produtos e nas relações estabelecidas com fornecedores e clientes. Conhecer "todo mundo", saber lidar com preços de produtos e com normas formais e informais de utilização das "pedras" são algumas das exigências presentes entre os pesquisados. Finalmente, pôde-se observar que a dinâmica de comercialização instituída no galpão vem reproduzindo mecanismos de dependência e subalternidade entre comerciantes mais capitalizados e os demais atores.
\end{abstract}

Palavras-chaves: Cecaf, Ceasa, agricultura familiar, comercialização.

Abstract: This research analyzes the social dynamics of the commercialization warehouse of family farming (Cecaf), within the scope of Ceasa, considering the social diversity, associative bases, strategies of commercialization and local disputes for the use of space. How do the daily dynamics of

Data de submissão: 7 de junho de 2017. Data de aceite: 18 de junho de 2018.

1. Universidade Federal de Pernambuco (UFPE), Recife (PE), Brasil. E-mails: julianagdemoraes@gmail.com; marialuizapires@gmail.com 
310 Agricultura familiar e mercados atacadistas: dinâmicas sociais da Central de Comercialização da Agricultura Familiar (Cecaf/Ceasa) em Recife - Pernambuco

commercialization set up in Cecaf and who are the social actors are some of questions that lead this research. This work involved 38 interviewees, among commercial farmers and managers. Created with the purpose to serve exclusively Pronaf beneficiary family farming, Cecaf needed to broaden its target audience, given the scarcity of users that fulfilled this criterion, favoring the installation of a diversity of actors. This commercialization experiences define specific way of life and work which are nourished by a constant learning from the buying and selling strategies and through the relationships established with suppliers and customers. Knowing "everybody", knowing how to deal with prices of products and the formal and informal rules for use of the "stones" are some of the requirements presented among farmers surveyed. Finally, it was possible to observe that the dynamics of commercialization reproduces mechanisms of dependency and subordination between more capitalized traders and other players.

Key-words: Cecaf, Ceasa, family farming, markets.

JEL: Q18 - Agricultural policy; Food policy

\section{Introdução}

Este trabalho analisa as dinâmicas sociais de funcionamento da Central de Comercialização da Agricultura Familiar (Cecaf), localizado no Centro de Abastecimento Logístico de Pernambuco (Ceasa-PE/O.S), em Recife, considerando a sua diversidade social, as bases associativas, as estratégias de comercialização e as disputas locais de uso do espaço. Mais especificamente, este trabalho objetiva situar o processo de ocupação do galpão, identificando as dificuldades vivenciadas no cotidiano dos agricultores, no esforço de garantir a sua permanência no local.

Concebidas na década de 1960, as Ceasas foram, durante muitos anos, a única referência pública para o abastecimento de varejões e mercados, bem como para a definição de padrões de qualidade, preços e classificação de produtos (Belik \& Maluf, 2000). Em meio às propostas de privatização dos canais públicos de comercialização de alimentos, já iniciadas pelo governo brasileiro no final da década de 1980 e impulsionadas a partir de 1990, as Ceasas foram dominadas pelo segmento supermercadista, favorecendo, assim, as grandes redes de distribuição (Belik \& Cunha, 2015).

Mediante a restruturação das políticas governamentais, o abastecimento alimentar passa, então, a responder às instâncias normativas internacionais, favorecendo a mobilidade das empresas em colonizarem todo o setor agroalimentar, eliminando as fronteiras sociais e espaciais regionalmente constituídas (Bonanno, 2016). Belik \& Cunha (2015) admitem que, diferente do setor público, estas redes conseguem promover e gerir, com eficiência, a escassez e a oferta de produtos, impulsionando novos hábitos de consumo adequados ao seu perfil de oferta. Ainda para estes autores, o abandono das ações públicas de abastecimento afetou diretamente a oferta de espaços de comercialização para a agricultura familiar, acarretando uma situação de maior vulnerabilidade à uma categoria identificada historicamente como um "setor bloqueado, impossibilitado de desenvolver suas potencialidades enquanto forma social específica de produção" (Wanderley, 1999, p.8).

Com o propósito de garantir o fortalecimento da agricultura familiar, observou-se, a partir da década de 2000, um esforço do governo brasileiro em promover ações em torno da abertura dos canais de comercialização para os seus produtos (Belik \& Cunha, 2015). No rol dessas iniciativas, alguns entrepostos, a exemplo dos estados

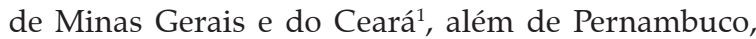
criaram galpões exclusivos para os pequenos produtores, permitindo, ao mesmo tempo, preços mais acessíveis aos consumidores. No contexto particularmente de Pernambuco, esse esforço se materializou, em 2005, com a criação da Central de Comercialização da Agricultura Familiar (Cecaf), com recursos do Ministério do Desenvolvimento Agrário (MDA), objeto de investigação deste trabalho.

Embora projetada para uso exclusivo de agricultores familiares beneficiados pelo Programa Nacional de Fortalecimento da Agricultura familiar (Pronaf), a Cecaf passou também a incorporar comerciantes e

1 Sobre essas experiências, ver Cunha (2013) e Mourão (2007). 
agricultores sem vínculos com o programa, muitos dos quais já tinham sido participantes de feiras que, habitualmente, funcionavam no interior do Ceasa-PE (Ceasa-PE/O.S., 2008). Habitualmente identificada por estes atores como "galpão do coentro," a Cecaf engloba populações categorizadas pela própria instituição, como "agricultores comerciantes", "agricultores produtores" e "comerciantes parceiros". Para os propósitos dessa pesquisa, privilegiou-se a categoria dos agricultores comerciantes como objeto de análise. A decisão dessa escolha pautou-se no fato de que essa categoria, além de acumular simultaneamente o conhecimento da produção e da comercialização, permanece por mais tempo no galpão, tendo mais informações sobre a dinâmica de comercialização naquele espaço, o que tenderia a atender melhor aos propósitos da pesquisa. Como se caracterizam os agricultores comerciantes que participam da dinâmica de comercialização da Cecaf? Como se estabeleceu o processo de ocupação deste espaço por estes atores? Como se configura o cotidiano da comercialização na Cecaf, na relação com outros usuários do galpão? No intuito de responder a estas questões, o galpão será aqui considerado como espaço de sociabilidades e de disputas, no âmbito de um mercado subordinado às estruturas econômicas externas e internas.

A categoria "agricultores", agrupada em número de 140 pessoas, representa $62 \%$ do galpão, e está dividida em dois subgrupos: 71 "agricultores produtores" e 69 "agricultores comerciantes", como se pode observar na tabela 1:

No caso em apreço, a amostra foi definida a partir da população de 69 "agricultores comerciantes" (49\% do universo total de agricultores do banco de dados de 2014), chegando-se, assim, a um número de 64 agricultores

Tabela 1. Categorias sociais cadastradas na Cecaf/Ceasa-PE

\begin{tabular}{lcc}
\hline Categorias cadastradas & Freq. absoluta & Freq. relativa \\
\hline Agricultores & 140 & $62 \%$ \\
Agricultor produtor & 71 & $51 \%$ \\
Agricultor comerciante & 69 & $49 \%$ \\
Comerciante parceiro & 85 & $38 \%$ \\
Cadastrados total & 225 & $100 \%$ \\
\hline
\end{tabular}

Fonte: dados cadastrais cedidos pelo Detec/CEASA-PE O.S. comerciantes $^{2}$. Entretanto, considerando a natureza qualitativa da pesquisa, realizou-se um segundo cálculo para a redução da amostra, obtendo um número de 34 indivíduos, representando $24 \%$ do universo total de agricultores ${ }^{3}$. Assim, a pesquisa contou com a narrativa de 32 homens e duas mulheres desta categoria.

Além desses, como forma de ampliar o conhecimento sobre o processo inicial de ocupação da Cecaf, foram entrevistados dois ex-gestores responsáveis pela implementação do projeto. Contou-se, também, com as informações do atual gerente do galpão e de um gestor de uma cooperativa integrante da Cecaf, como fontes importantes para a compreensão das dinâmicas instituídas no cotidiano do galpão; o que totalizou população de 38 entrevistados. $\mathrm{O}$ acompanhamento e o registro das rotinas de comercialização no galpão, além da realização de entrevistas semiestruturadas, ocorreram entre novembro de 2015 e outubro de 2016. Para dar conta das especificidades da dinâmica de funcionamento, as visitas foram realizadas nos mais distintos horários, algumas das vezes iniciando-se nas madrugadas, em torno das $3 \mathrm{~h}$.

Estabeleceu-se, como eixo analítico, a relação entre políticas públicas e construção de mercados para a agricultura familiar. A relação entre Estado e sociedade civil marca, nos anos 2000, uma preocupação em torno da construção de mercados voltados à mitigação da fome e à garantia da segurança alimentar, e está registrada em estudos de Grisa \& Schneider (2015) e de Niederle et al. (2013), entre outros. Voltando-se para a construção destas políticas, a literatura especializada também chama a atenção para a necessidade das redes participativas entre gestores e grupos beneficiários, de modo a permitir a agricultores a apropriação da estrutura operacional destes espaços (Souza-Esquerdo \& Bergamasco, 2014; Maluf, 2004; Sabourin, 2009). A ausência dessas redes, como no caso em questão, também nos remete a dar particular atenção aos conflitos e assimetrias existentes entre os atores envolvidos na Cecaf. Finalmente, a incompatibilidade entre as estruturas dos mercados atacadistas e as dimensões locais da produção familiar,

2 Cálculo de Amostragem Proporcional proposto por Barbetta (2008), definido como nível de confiança o valor de 95\% de probabilidade, com erro amostral de $3 \%$.

3 Este resultado teve como base o Cálculo de Amostragem Finita, também nos moldes propostos por Barbetta (2008). 
312 Agricultura familiar e mercados atacadistas: dinâmicas sociais da Central de Comercialização da Agricultura Familiar (Cecaf/Ceasa) em Recife - Pernambuco

tal como já destacado por Cunha (2013), também se faz presente no âmbito desta investigação.

O trabalho está dividido em três sessões, além da introdução. A primeira situa o processo de criação das Ceasas brasileiras, associando tal iniciativa ao esforço do governo com a modernização da cadeia produtiva de alimentos. As especificidades do Ceasa de Pernambuco também foram exploradas nessa sessão. A segunda sessão recai sobre a análise da Central de Comercialização da Agricultura Familiar (Cecaf), sublinhando as diretrizes contidas no seu projeto inicial de constituição. Apresenta-se também o perfil dos usuários da Cecaf, destacando as particularidades dos agricultores comerciantes entrevistados. Os custos relativos à comercialização nesse galpão são também apresentados nessa parte. Além, disso, são analisadas as especificidades que caracterizam a comercialização na Cecaf, dando particular destaque à forma de ocupação do espaço, aos tipos de produtos ofertados e à forma como são definidos os preços desses produtos. Na terceira sessão, foram tecidas as considerações finais, destacando os pontos mais relevantes da análise, dentro de um esforço de síntese da discussão.

A importância deste trabalho está em ampliar a compreensão do modo como os agricultores que comercializam nas Ceasas estruturam a sua reprodução social, o que, por conseguinte, implica a possibilidade de oferecer subsídios à elaboração de políticas públicas voltadas para a construção de mercados para a agricultura familiar.

\section{A criação do sistema Ceasa e sua articulação com a produção familiar}

Até a década de 1960, a comercialização de hortaliças, frutas e de grãos nos centros urbanos brasileiros era realizada nas chamadas feiras livres (Mourão \& Magalhães, 2009). Estas eram tradicionalmente abastecidas pela pequena produção doméstica das diversas formas do campesinato. Belik \& Maluf (2000) reiteram essa ideia, chamando a atenção para o desprezo do latifúndio às culturas alimentares, considerando-as como de menor importância.

As feiras livres refletiam uma limitada cobertura da oferta de alimentos à população urbana, além de expressarem graves problemas sanitários (Faulin \& Azevedo, 2003; Mourão \& Magalhães, 2009). Sem estruturação e sem conhecimento de mercado, caracterizavam-se como uma atividade marginal. "Tão marginal que a comercialização se dava na rua, literalmente" (Mourão, 2008. p. 6). Este quadro, alimentado por uma concepção desenvolvimentista, levou o governo brasileiro a implantar, ainda na década de 1960, uma política de apoio à modernização agrícola industrial, que percorria toda a cadeia produtiva, mediante a regulação da logística, preços e estoques (Belik \& Maluf, 2000).

Grisa \& Schneider (2015), definindo o caráter atuante do Estado na implementação das infraestruturas produtivas, destacam que a execução desta política se dá a partir de referenciais macroeconômico e setorial. Não sem razão, tais ações, ainda que voltadas para solucionar as dificuldades no abastecimento alimentar interno e os sintomas de crise econômica, não puderam evitar a emergência de críticas ao padrão excludente das medidas governamentais de industrialização do País (Grisa \& Schneider, 2015).

A estruturação da política de abastecimento interno também pressupunha a criação de entrepostos atacadistas e de sistemas de armazenagem integralmente regulados pelo Estado, por todo o País. As primeiras experiências foram, então, implementadas no Recife, em 1962, por meio da Lei n. 6, de 26 de setembro, que autoriza a criação do Centro de Abastecimento de Pernambuco S/ A (Capesa), vinculada à Sudene; e, em São Paulo, em 1969, por meio da fusão entre o Centro Estadual de Abastecimento (Ceasa) e a Companhia de Armazéns Gerais do Estado de São Paulo (Cagesp) (Mourão \& Magalhães, 2009).

Na década de 1970, o governo cria, por meio do Decreto n. 70.502 de 11/05/1972, um sistema de intervenção direta sobre as Centrais de Abastecimento, conhecido como Sistema Nacional de Centrais de Abastecimento (Sinac), que esteve vigente entre 1972 e 1988, sob a coordenação da empresa estatal Companhia Brasileira de Alimentos (COBAL) (Belik \& Maluf, 2000). O Sinac foi implantado por meio de uma articulação do governo federal com estados e municípios, com o objetivo de estabelecer uma rede de informações técnicas para aprimoramento e padronização do sistema de distribuição de alimentos. Nessa direção, a modernização dos equipamentos de varejo, redução dos custos de transação, eliminação das assimetrias na informação entre os agentes da cadeia produtiva e aprimoramento da qualidade dos produtos constituíam alguns dos seus objetivos (Cunha \& Campos, 2008). 
O ritmo de expansão do Sinac acompanhou o período de grandes investimentos em infraestrutura experimentado na década de 1970, revelando-se com a criação de 34 centros atacadistas (no caso, as Ceasas), 32 mercados do produtor e 158 unidades de varejo (Mourão, 2008). Este período se traduz pela trajetória expansionista da economia brasileira, formada por um arranjo organizacional impulsionado pelo capital internacional, cuja estratégia consistia em estabelecer normas, padrões e técnicas, associadas às vantagens estritamente econômicas (Cunha, 2006). O esgotamento desse modelo teve como consequência o desmonte do Sinac, no final da década de 1980, como resultado da política de privatização de empresas estatais, na qual já se previa a possibilidade de privatização de 21 Ceasas, por meio do Decreto n. 93.611 de 21.11.1986.

O decreto sublinhado transferia o controle acionário da Cobal para estados e municípios, denunciando a desarticulação de sua coordenação geral, bem como a ausência de uma visão estratégica de longo prazo (Cunha, 2006). Para Mourão (2008. p. 3), o fim do Sinac representou a quebra do "vaso comunicante que irrigava o sistema com informações e conhecimento". Ao que complementa: "Tínhamos um Brasil e, da noite para o dia, passamos a ter 21 "brasis" [...]. Houve, portanto, uma verdadeira "queima de Biblioteca de Alexandria" (Mourão, 2008. p. 3). O que, por conseguinte, traria graves implicações as Ceasas, ainda desprovidas de uma estrutura consolidada para assumir, com autonomia, as suas linhas operacionais. Ademais, as Ceasas não foram capazes de acompanhar as mudanças no padrão de consumo das famílias urbanas, momento em que as centrais passavam a ser ocupadas por estruturas privadas de comercialização, ampliando o poderio e a influência dos agentes privados na estratificação do consumo e na sofisticação dos sistemas de logísticas no âmbito dos alimentos (Belik \& Maluf, 2000; Cunha, 2013).

A década de 1980 inaugura a abertura democrática associada ao reconhecimento, por parte do governo, das particularidades da produção familiar, com a elaboração de políticas voltadas a esse setor. Entretanto, como observam, os esperados benefícios vinculados à produção familiar não foram suficientemente alcançados em função da inabilidade do Estado "em incorporar, em suas metodologias de atendimento, as demandas deste segmento" (Grisa \& Schneider, 2015, p. 130). Segundo Grisa \& Schneider (2015), esta inabilidade do Estado acentuou-se quando o governo, com intuito de superar a crise financeira de 1980 e 1990, passa a operar em uma economia de contenção de gastos com as políticas agrícolas e com a redução das tarifas de importação de produtos alimentares.

Consolidava-se, paulatinamente, um arranjo organizacional de mercantilização da cadeia alimentar, que aparece acentuadamente agravado, a partir dos anos 1990, quando a produção e a distribuição de alimentos passam a operar numa lógica sustentada por um projeto neoliberal da Organização Mundial do Comércio - OMC (Bonanno, 2003; Ploeg, 2008). Isso ocorre num tempo em que, de forma orquestrada, as corporações internacionais ampliam o seu controle sobre as cadeias agroalimentares, incluindo a padronização das normas de comercialização de vegetais frescos (Bonanno, 2003; Cavalcanti, 2004).

Sublinha Bonanno (2003; 2016), nesse sentido, que uma das principais características desse período teria sido a mobilidade das empresas em colonizar e mercantilizar os países periféricos, resultando na desigualdade do trabalho, dos recursos e do acesso aos produtos alimentares. Com efeito, a desarticulação do sistema público de abastecimento alimentar, na década de 1990, associou-se ao fortalecimento de cadeias varejistas agroalimentares privadas, que passaram a dominar vários setores da alimentação.

As funções de gestão das Ceasas ficaram restritas à prestação de serviços infraestruturais de apoio à comercialização, como provimento de energia, água e esgoto, normas de trânsito, urbanização, manutenção básica de vias e dos serviços de fiscalização, limpeza e vigilância, dentro do que Mourão (2008, p. 23) denomina como "funções de condomínio". Diante deste cenário, o corpo de diretores de algumas Centrais instituiu, na década de 2000, a Associação Brasileira de Centrais de Abastecimento (Abracen), na tentativa de manter uma agência coordenadora das ações. Para tanto, foi desenvolvido, sob a responsabilidade da Companhia nacional de Abastecimento (Conab), o Sistema de Informações dos Mercados de Abastecimento do Brasil (Simab), com o propósito, dentre outros, de sistematizar dados sobre os produtos que circulam entre os entrepostos (Mourão, 2007).

Com a criação do Simab, as Centrais retomam a regulamentação sob os preços, no âmbito dos mercados regionais de hortifrúti (Cunha \& Campos, 2008). Passando a ser operacionalizado com base em uma dicotomia público-privada, o sistema engloba um conjunto de 72 entrepostos presentes em 21 estados. Tais entrepostos são 
314 Agricultura familiar e mercados atacadistas: dinâmicas sociais da Central de Comercialização da Agricultura Familiar (Cecaf/Ceasa) em Recife - Pernambuco

administrados por 15 instituições estaduais, 19 municipais, dois federais e cinco organizações conveniadas (Wegner \& Belik, 2012). De um lado, registra-se a função pública de regulamentação do comércio e das normas de uso do espaço de comercialização e, de outro, a função privada, relacionada à logística dos comércios varejista e atacadista, por meio de mais de 10 mil empresas responsáveis pela comercialização de 15,5 milhões de toneladas anuais de alimentos, com movimentação comercial em torno de U\$ 10 bilhões anuais (Belik \& Cunha, 2015; Cunha \& Campos, 2008).

Na busca por maior autonomia da gestão pública, as Ceasas elaboraram, em 2005, o Programa Brasileiro de Modernização do Mercado (Prohort), coordenado pela Conab. A partir da recomposição de um sistema único voltado para a integração das bases de dados, da troca de informações e da criação de mecanismos comuns de capacitação tecnológica, este programa tem por objetivo a revitalização das Ceasas brasileiras (Cunha, 2006, Mourão, 2008).

Nesse contexto de restruturação, observou-se, também, um esforço na implementação de projetos sociais passíveis de atender às necessidades de uma população flutuante de trabalhadores, produtores, entre outras categorias, presentes habitualmente nos entrepostos das Ceasas (Cunha, 2006). No foco destes projetos, está o incentivo à produção e à comercialização dos produtos da agricultura familiar, mediante agregação de valor a estes produtos e garantia da segurança alimentar para a população, por meio da oferta de produtos de qualidade (Mourão, 2008). Com esse propósito, foram implementados alguns programas de segurança alimentar, como bancos de alimentos e iniciativas para reduzir o desperdício. No que diz respeito ao apoio à agricultura familiar, foram instalados galpões de comercialização exclusivos a este setor, que, no caso de Pernambuco, ficou conhecido como Central de Comercialização da Agricultura Familiar (Cecaf).

\section{O Ceasa de Recife - Pernambuco}

A Central de Recife, sob a denominação de Central de Abastecimento de Pernambuco S/A (Capesa), foi a primeira experiência nesse campo instalada no Brasil pelo governo federal, ainda em 1962. Em 1963, a Capesa teve sua atuação ampliada para todo o Nordeste, passando a ser denominada Central de Abastecimento do Nordeste S / A (Canesa). Em 1968, a Canesa mudou a razão social para Central de Abastecimento do Recife (Care) que, por sua vez, inaugurou, em 1973, a Central de Abastecimento de Pernambuco (Ceasape/O.S). A partir de uma parceria entre Estado e sociedade civil, sob os auspícios da Secretaria Estadual de Agricultura e Reforma Agrária, o Ceasa-PE tornou-se, em 2004, a primeira no Brasil a adquirir o status de organização social (Ceasa - PE/O.S.). Ainda que a luta pela obtenção da O.S tenha sido motivada pelo desejo de ampliação dos canais de participação e pela minimização das distorções junto aos usuários do sistema quanto aos mecanismos de comercialização e logística, este formato não se mostrou capaz de atender completamente a esses apelos (Nascimento, 2008).

O Ceasa - PE/O.S., com área de $580.000 \mathrm{~m}^{2}$ e 48 galpões, se constitui como o quarto maior entreposto do Brasil e o primeiro maior do Norte e Nordeste, garantindo a circulação de 55.000 mil pessoas mensalmente, com movimentação financeira de R\$ 190 milhões mensais (Ceasa-PE/O.S., 2017). Um conjunto de 1.300 permissionários fixos - pessoas autorizadas a comercializarem nos galpões - compõe o quadro dos comerciantes e distribuidores que ocupa as lojas do entreposto, mediante pagamento de um aluguel mensal. Diferente desses, o contingente de comerciantes não fixos depende do pagamento de uma taxa diária pelo uso do metro quadrado do piso dos galpões, habitualmente denominado de "pedra".

O plano de trabalho do Ceasa-PE/ O.S (2015/2016) estabelece, dentre as suas linhas de ação para o fomento da base social, a ampliação das estruturas físicas e adequação da política de comercialização (em termos de disseminação de informações comerciais e de organização para uma produção programada) para os beneficiários diretos do Pronaf e para o conjunto de agricultores de base familiar. No atendimento destes propósitos, o Ceasa-PE/O.S. disponibiliza três galpões abertos e setorizados, denominados GLP I, II, III, que funcionam de forma semelhante às feiras livres. Mais recentemente, em 2005, o Centro construiu, com recurso de R $\$ 225$ milhões oriundos da pasta do MDA, um quarto galpão para uso exclusivo da agricultura familiar. Este galpão foi denominado de Central de Comercialização da Agricultura Familiar - Cecaf, que será descrito a seguir. 


\section{A Central de Comercialização da Agricultura Familiar - Cecaf}

A Cecaf foi projetada para acomodar três mil agricultores beneficiários do Pronaf, mediante a participação em processos formativos, com estímulo para a formação de associações e cooperativas. A Cecaf contou, a princípio, com um comitê composto por um conjunto de 14 entidades $^{4}$, com o propósito de planejar o funcionamento do galpão, de modo a garantir o atendimento das necessidades dos agricultores. A proposta pautava-se na participação paritária de agricultores e entidades representativas em todas as instâncias decisórias, como ressaltado por um gestor do MDA: “50\% ligadas aos organismos governamentais e $50 \%$ ligadas às organizações dos agricultores." Tal propósito, entretanto, não chegou a ser plenamente implementado, dado o clima de disputa instaurado entre gestores e diretores do entreposto, favorecendo a estruturação de uma estrutura de trabalho verticalizada: "Foi uma coisa muito criada de cima pra baixo e acabou não dando certo porque não tinha uma interlocução entre os setores" (Gestor do MDA). Soma-se a isso a falta de recursos para a continuidade do trabalho, que previa uma formação permanente dos participantes.

Uma das primeiras ações deste comitê foi a promoção de uma convocatória pública para atrair a participação dos agricultores e a sua adesão ao projeto da Cecaf. O número de agricultores familiares participantes dessa inauguração variou consideravelmente entre as fontes de informação. Para uns, foram " 450 agricultores com seus produtos já para serem comercializados" (Gestora da Arco Norte) e, para outros, esse número mais do que dobrava, atingindo 1.074 agricultores (Ceasa - PE / O.S., 2008). O que se constatou, entretanto, foi uma enorme dificuldade de preenchimento dos requisitos previstos

\footnotetext{
4 Participaram desse comitê as seguintes entidades: Secretaria de Agricultura e Reforma Agrária (Sara); Secretaria de Desenvolvimento Territorial (MDA/SDT); Instituto Agronômico de Pernambuco (IPA); Projeto Renascer, Federação dos Trabalhadores na Agricultura (Fetape), Serviço de Tecnologia Alternativa (Serta), Federação de Orgãos para Assistência Social e Educacional (Fase), Agência Regional do Agronegócio Familiar do Sub-médio do São Francisco (Agromesf), Cooperativa dos Profissionais em Atividades Gerais (Coopagel), Centro de Mulheres do Cabo (CMC), Centro de Educação do Trabalhador Rural, Sindicato do Comércio de Hortícolas, Flores e Plantas de Estado de PE (SINDfrutas), Associação dos Usuários e Comerciantes do Ceasa/PE (Assucere) e Agência Regional de Comercialização da Mata Norte de Pernambuco (Arco Norte).
}

no projeto inicial, exigindo a abertura da proposta para outros atores além dos beneficiários do Pronaf. Nesse contexto, o comitê gestor foi desfeito tão logo se iniciou o funcionamento do galpão.

A tarefa de ampliar o acesso à Cecaf para além dos agricultores familiares ficou sob a responsabilidade da Agência Nacional de Comercialização da Zona da Mata Norte (Arco Norte) $)^{5}$, via convênio com o Projeto Dom Hélder Câmara (PDHC). Este último ficava responsável pela articulação e organização dos interessados em participar da Cecaf. A escolha do $\mathrm{PDHC}$ se deu graças à experiência desta entidade com a execução de programas voltados ao fortalecimento dos projetos de reforma agrária e da agricultura familiar, especialmente na região do semiárido nordestino. Especializada no desenvolvimento de metodologias participativas, o PDHC vem orientando as ações de políticas públicas de combate à pobreza e de promoção de desenvolvimento sustentável (Teixeira \& Pires, 2017)

Em meados de 2007, a Arco Norte repassou os recursos para a Federação dos Agricultores do Estado de Pernambuco (Fetape), em atendimento as reivindicações desta federação pela gestão do galpão. A gestão da Fetape permaneceu até 2014, quando passou para o domínio exclusivo do Ceasa-PE/O.S. Segundo relatos, a passagem da Fetape pelo galpão ficou restrita à ação de uma profissional ligada à entidade, identificada pelos feirantes como a "moça do Estado" ou como a "funcionária do Ceasa." Esta atuava na orientação sobre emissão de documentos, informações sobre benefícios previdenciários, regulação de cadastros e orientações sobre sindicalização. Mesmo assim, os discursos dos entrevistados não sinalizavam a representatividade e a importância da Fetape no âmbito da Cecaf. Atualmente, a gerência do conjunto dos galpões do Ceasa-PE/O.S, o que inclui o galpão da Cecaf, cabe a um ex-integrante do comitê gestor da Cecaf, na época representante do Ceasa-PE.

Para os agricultores comerciantes, houve uma melhoria na atuação institucional a partir desta nova gestão, dada a atenção prestada por esse técnico aos assuntos de seus interesses. Diferentemente do antigo gerente, descrito como "agitado" (Agricultor, Chã Grande,

\footnotetext{
Esta agência integrava as Agências Nacionais de Comercialização (Arco-BR) criadas pelo governo federal, em 2002, com o objetivo de apoiar e organizar os agricultores familiares na comercialização de seus produtos.
} 
316 - Agricultura familiar e mercados atacadistas: dinâmicas sociais da Central de Comercialização da Agricultura Familiar (Cecaf/Ceasa) em Recife - Pernambuco

55 anos) e autoritário: "Na outra gestão a gente era cachorro" (Gestor da Coopafa), o atual gerente "pensa no agricultor" (Agricultora, Recife, 42 anos) porque abre espaços para o diálogo. Entretanto, o reconhecimento da melhoria do atual processo gestionário não implica, para os usuários do galpão, que o projeto esteja atendendo ao conjunto de interesses da agricultura familiar, como será discutido mais adiante.

\subsection{Os usuários da Cecaf}

Seguindo a titulação definida pela Cecaf, são considerados usuários do galpão os "agricultores produtores," os "agricultores comerciantes" e os "comerciantes parceiros." Os agricultores produtores são aqueles que produzem e repassam a sua produção para o conjunto dos feirantes. Não se utilizando de pedras para a comercialização, sua permanência na Cecaf é efêmera, quase sempre restrita às madrugadas durante a entrega do produto aos feirantes. Os agricultores comerciantes, por sua vez, além de trazerem seus produtos e de outros agricultores, também costumam comprar produtos de fornecedores para comercializá-los, permanecendo de forma mais assídua na Cecaf.

Como já sublinhado neste trabalho, os dois primeiros grupos perfazem um total de 140 usuários, o que equivale a $62 \%$ do total de usuários do galpão.

Os comerciantes parceiros, por sua vez, abrangem 85 pessoas, representando $38 \%$ dos integrantes da Cecaf. Esses últimos se caracterizam pela atividade de receber e repassar as mercadorias dos agricultores, sendo, por conta disso, considerados como atravessadores. Entretanto, o caráter de atravessador não retira o prestígio que essa categoria goza entre os feirantes, quando garante ao agricultor o escoamento regular de seu produto na Cecaf. Nesse sentido, como afirma um agricultor referindo-se ao comerciante parceiro: "ele tem a obrigação de pegar a minha mercadoria, na falta ou na boia. É um compromisso." (Agricultor, Passira, 48 anos). O prestígio atribuído a essa categoria tem favorecido o seu controle sobre o conjunto dos agricultores comerciantes, reproduzindo mecanismos de dependência e subalternidade, como ilustrado no discurso: "É o meu patrão. Quem movimenta esse galpão todinho é ele" (Agricultor, Passira, 48 anos).

Além de agricultores e comerciantes, outros atores que não estão formalmente cadastrados no galpão também contribuem para a sua dinâmica social. É o caso, por exemplo, de um grupo de atravessadores conhecidos localmente como "siris". A razão do nome dá-se pela sua agilidade em comprar um dado produto, retalhando-o para vendê-lo em pequenas quantidades. Para tanto, os siris abordam os clientes antes que estes cheguem às bancadas dos feirantes, obstruindo, muitas vezes, o fluxo de passagem pelos corredores. Essa forma de comercialização criada pelos siris estabelece uma concorrência com os demais feirantes, resultando, quase sempre, em conflitos em torno dos espaços e dos clientes.

Além dos siris, há também os "fretistas", um grupo que se ocupa com o descarregamento dos caminhões que abastecem a Cecaf. Trata-se de uma categoria igualmente não cadastrada na Cecaf, e de pouca visibilidade entre o conjunto dos atores que ali transitam. Além desses, outros grupos de trabalhadores podem ser facilmente identificados, a exemplo dos desfolhadores de repolho, separadores de trouxas de coentro e de mercadorias de segunda linha, dos legumes tidos como "feios", destinados para restaurantes, por menor preço. A sua função é de fazer uma triagem dos produtos, dando-lhes, assim, destinos e preços que variam em função da qualidade.

Além dos feirantes e trabalhadores, a dinâmica da Cecaf gira em torno dos clientes e dos funcionários do Ceasa-PE. Dentre os clientes, registra-se um maior contingente de comerciantes de feiras livres, especialmente dos bairros de Casa Amarela (Recife) e de Peixinhos (Olinda). Donos de pequenas quitandas e restaurantes do Recife compõem o segundo maior grupo de clientes, seguidos pelas donas de casas, que costumam frequentar o galpão preferencialmente aos sábados. Em todos os casos, as negociações são realizadas dispensando os mecanismos formais de comercialização, como notas fiscais, promissórias etc. No tocante ao aporte administrativo, o galpão conta com um gerente de mercado que, por meio dos fiscais de área responsáveis pelo recolhimento das taxas e aluguéis de todos os galpões do Ceasa, administra os recursos e todo o funcionamento do galpão. São elencados, ainda, os funcionários de outros setores, como os técnicos para reparos, limpeza e serviços infraestruturais.

\subsection{Perfil da amostra dos agricultores entrevistados}

No tocante aos agricultores comerciantes entrevistados, 32 (94\%) são do sexo masculino e dois, (6\%) do sexo feminino, predominando a faixa etária entre 50 e 60 anos (46\%). Esse grupo é originário de três regióes do estado de Pernambuco: Zona da Mata Norte 
(50\%); Região Metropolitana do Recife (26\%) e Agreste $(24 \%)$. Os principais municípios a que se vinculam os agricultores são: Chã Grande (32\%) e Recife (24\%). Vale destacar que parte destes entrevistados de Recife compõe o grupo de agricultores urbanos do entorno do CeasaPE. Do total dos entrevistados, $50 \%$ são proprietários de terras, seguidos pelo grupo dos agricultores urbanos (23\%) que produzem em terrenos públicos.

Ferreira (2013) chama a atenção para o fato de que o ponto mais importante de manutenção desses terrenos constitui a proximidade com o Ceasa, permitindo o escoamento da produção, sem a qual não haveria a viabilidade de manutenção do negócio. $\mathrm{O}$ autor chama ainda a atenção para as interações sociais e trocas de conhecimento entre esses produtores e os da zona rural, observando que alguns feirantes já tenham migrado para as lavouras periurbanas, atraídos por algumas vantagens desse modelo de produção. Essas trocas que se dão entre populações rurais e urbanas desencadeadas pelas memórias culturais e práticas produtivas, permitindo que se desenvolvam atividades rurais nos espaços urbanos, já analisados por Santos (2008), podem ser definidas pelo que Cimadevilla \& Kenbel (2014) definem como rurbanidades.

Em menor proporção estão os assentados da reforma agrária (12\%), os agricultores posseiros $(9 \%)$ e os agricultores que cultivam em áreas arrendadas (6\%). A extensão das propriedades dos agricultores comerciantes variou entre 1,5 e 12 hectares, predominando as áreas menores que 5 ha (60\% dos entrevistados). Vale grifar também que, embora a grande maioria estivesse domiciliada na zona rural, apenas $9(26 \%)$ entrevistados participam de associações de moradores rurais, não tendo sido encontrado nenhum deles vinculado às cooperativas. Apesar disso, é comum nos seus discursos o reconhecimento da importância dessas associações para "arrumar uma feira pra você botar mercadoria, trazer projeto pra dentro da comunidade" (Agricultor, Vitória de $\mathrm{St}^{\circ}$ Antão, 39 anos).

Todos os entrevistados participam da Cecaf desde sua implantação, em 2005, contando-se, assim, até o momento da pesquisa, 12 anos de ocupação. No entanto, via de regra, a Cecaf não se constitui como a primeira experiência de comercialização na vida dos agricultores, como explicado por um entrevistado: "venho de longe. Já faz 27 anos. Já fui lá do 63, um galpão lá em cima perto da laranja. Saí girando, já fui pra ali, já fui pra aqui"
(Agricultor, Chã Grande, 62 anos). De todo modo, todos eles experimentaram um processo de deslocamento ou realocação em ao menos quatro etapas, não necessariamente sucessivas, quais sejam: "feira livre", "feira da lama", também conhecida como "feira do coentro", galpão 63 e galpão GLP III.

O funcionamento da Cecaf é diário e obedece ao horário do Ceasa ${ }^{6}$. Entretanto, a ocupação dos diversos turnos segue a conveniência dos agricultores comerciantes. Nesse contexto, cerca de $40 \%$ dos entrevistados não comercializam todos os dias, tendo chances de alternar o trabalho na lavoura com a comercialização no galpão. Apenas 30\% desse grupo dedica-se diariamente à produção e à comercialização. Constatou-se, também, que, dos $30 \%$ restantes, metade se dedica à lavoura apenas nos finais de semana, e a outra metade mantém a unidade produtiva desativada.

Independentemente do volume produzido, constatou-se que um contingente de 21 agricultores entrevistados (62\%) está domiciliado em propriedades rurais e 13 residem na zona urbana (38\%), dos quais dois (6\%) ainda mantêm a família vivendo na zona rural. Tendo em vista a necessidade de minimizar custos e reduzir o tempo de deslocamentos para o galpão, não raramente os agricultores pernoitam em casas alugadas, ou em um albergue disponibilizado pelo Ceasa-PE, com tarifa subsidiada. Referindo-se à necessidade de permanência diária na comercialização, um dos entrevistados indaga, "como é que se vive direto dentro do mato?" (Agricultor, São Joaquim do Monte, 57 anos). Sendo assim, considera-se que o afastamento da propriedade e a concomitante assimilação das atividades urbanas passam a definir a rotina de trabalho e de vida desses produtores. Como quer que seja, a maioria dos agricultores comerciantes precisa enfrentar uma intensa jornada de trabalho, tendo em vista o tempo gasto na produção, transporte e comercialização das mercadorias. Não sem razão, "o que eu tenho de reclamação é o cansaço," afirmou um dos entrevistados (Agricultor, Recife, 33 anos).

\footnotetext{
6 Nas segundas-feiras, a abertura do galpão ocorre à meia-noite, encerrando as atividades às $18 \mathrm{~h}$; nas terças, quartas e quintas-feiras, o período estende-se das $3 \mathrm{~h}$ às 18h. Nas sextas-feiras, as atividades são encerradas uma hora mais tarde, indo das $3 \mathrm{~h}$ às $19 \mathrm{~h}$, enquanto aos sábados o horário se restringe das $3 \mathrm{~h}$ às $13 \mathrm{~h}$.
} 
318 Agricultura familiar e mercados atacadistas: dinâmicas sociais da Central de Comercialização da Agricultura Familiar (Cecaf/Ceasa) em Recife - Pernambuco

\subsection{As especificidades que caracterizam a comercialização na Cecaf}

De modo geral, a comercialização na Cecaf se caracteriza pela presença de redes de interação entre agricultores, comerciantes, técnicos e clientes, garantindo a circulação de informações, de mercadorias e a constante prática da negociação. De acordo com Garcia Jr. (1989), os agricultores que se concentram em feiras não estão na condição de produtores, mas de negociantes, especialistas, com certas habilidades específicas para lidar com flutuação de preços, garantindo-lhes maior autonomia. As narrativas dos entrevistados corroboram esta premissa, como observado: "Eu comercializo para apurar o que é meu. Eu vou deixar pros outros, é?" (Agricultor, João Alfredo, 58 anos). A aptidão para negociar é quase sempre configurada como uma herança passada de pais para filhos, haja visto que "não é todo mundo que sabe negociar, que é desenrolado" (Agricultor, Catende, 52 anos). Contudo, reconhece-se também que a aptidão possa ser adquirida na prática cotidiana, seja na identificação dos pontos-chave de circulação de clientes, seja no aprimoramento da relação com fornecedores e clientes.

As redes de comercialização da Cecaf envolvem negociação de produtos em atacado e varejo. O atacado é mais comumente dirigido a comerciantes de feiras livres e quitandas sendo, quase sempre, desenvolvido pelos atores mais capitalizados, o que, no nosso caso, representa $38 \%$ da amostra. O varejo, por outro lado, constitui a modalidade mais comumente utilizada, envolvendo $62 \%$ dos entrevistados. Vale ressaltar, entretanto, que essa modalidade de comercialização pode ser utilizada por atacadistas, com o intuito de reduzir a quantidade de sobras de produtos perecíveis. Trata-se de uma situação frequentemente vivenciada pelos horticultores do interior do estado: "Se não retalhar, vai boiar. Aí eu boto pros meninos: 20 bolsa pra um, 10 bolsa pro outro" (Agricultor, Chã Grande, 47 anos).

No caso em questão, "os meninos" são "os siris", já mencionados neste trabalho, referindo-se aos pequenos comerciantes itinerantes que passam a ser incluídos, ainda que de forma periférica, nessa rede. De acordo com um gestor do Ceasa-PE/O.S: "o varejo é o homem da periferia, o pessoal do morro, da região metropolitana, desempregado. Aí ele compra um molho de coentro daquele, vamos dizer, a $R \$ 30$, faz 50 mãos de coentro e vai vender a R $\$ 2$ cada uma" (Gerente do Ceasa-PE/O.S).
Outros participantes também atuam na condição de varejistas. Trata-se dos agricultores urbanos que produzem em lavouras urbanas no entorno do entreposto, sob monitoramento do Ceasa-PE/OS. Embora grande parte da comercialização seja canalizada para a Cecaf, estes agricultores costumam também comercializar seus produtos na própria lavoura.

\subsection{Os custos de comercialização}

Para se estabelecer na comercialização, além das habilidades sublinhadas, faz-se necessário que o feirante possua capital para lidar com todos os custos envolvidos: investimento na produção, contratação de empregados, aquisição ou aluguel de um veículo para o transporte da mercadoria, além do habitual pagamento das pedras. Ademais, a possibilidade de arcar com prejuízos, como perda da produção, dívidas de clientes e, sobretudo, sobras de mercadorias não vendidas, também está no rol destes custos. No contexto dessas despesas, a disponibilidade de um transporte é identificada como uma condição essencial para o exercício da atividade, como destacou um dos entrevistados: "Aqui, se é agricultor, tem que ter carro, senão, como faz? (Agricultor, João Alfredo, 58 anos). Entretanto, apenas 19 agricultores (56\%), de um total de 34 entrevistados, contam com transportes próprios. Entre os demais, sete agricultores $(21 \%)$ pagam o serviço de transporte e os oito (23\%) restantes são agricultores que plantam ao redor do Ceasa-PE/O.S. e que transportam seus produtos para o galpão em carros de mão, dada a proximidade com o local.

O descarregamento dos produtos dos agricultores motorizados requer o pagamento prévio de uma taxa, conhecida como romaneio ${ }^{7}$, definida a partir do peso das mercadorias. No entanto, o pagamento dessa taxa não assegura uma vaga nas proximidades do galpão, causando mal-estar entre aqueles que atribuem a ausência de vagas para os agricultores à falta de apoio institucional que assegure condições mínimas de trabalho para os agricultores familiares. A taxa de romaneio tem variado, entre os usuários do galpão, de $R \$ 130$ para $\mathrm{R} \$ 170$ por carga. São valores considerados muito elevados, inviabilizando o transporte de pequenos volumes, bem como a inserção de agricultores que não disponham desses recursos. Por conta disso, verifica-se que há um esforço considerável dos entrevistados no

Documento que discrimina os componentes de uma carga e os automóveis pelo número do chassi. 
sentido de carregarem os caminhões durante o percurso nas comunidades rurais, de modo a permitir completar a carga da mercadoria que chega ao galpão.

Soma-se aos custos a falta de apoio dispensada especialmente aos agricultores novatos, fato, aliás, observado por um entrevistado: "Tem que ser compreensivo com o agricultor. A gente é sofredor, trabalha todo dia da semana, vive dentro do roçado, no sol quente, vende a mercadoria aqui, então tem que ser bem recebido, bem atendido" (Agricultor, Chã Grande, 55 anos). Os agricultores também se ressentem da falta de segurança e, sobretudo, da ausência de políticas capazes de indenizar os prejuízos que comprometam a comercialização, como destacado por um entrevistado:

O pequeno agricultor não tem condição de tá aqui. Porque eu cobro uma bolsa de chuchu dessas, dá $R \$ 50$. Aí o pequeno podia tá aqui, mas ele pega um mês pra vender o chuchu caro, e 11 meses para vender barato, então não dá pro pequeno agricultor. Muito bom o projeto deles (da Cecaf), mas se oferecesse outras vantagens (Agricultor, Passira, 48 anos).

Finalmente, os agricultores também se queixam dos custos oriundos do atendimento à padronização das embalagens, instituída pelo Ceasa-PE. São caixas plásticas, em substituição às caixas de madeira, que atendem às exigências do mercado internacional e da Lei n. 9.972 do Ministério da Agricultura, Pecuária e Abastecimento (Brasil, 2000), e da Instrução Normativa Conjunta n. 009 de 2002, destinado a prevenir a contaminação e os custos relativos às perdas produzidas por embalagem $e$ transporte inadequado dos produtos, como já analisado por Fávero (2005) e Alves et al. (2013). A padronização das embalagens foi descrita como um "imposto alto, pra cima do agricultor" (Agricultor, Bom Jardim, 52 anos), devido ao custo de comprá-las e de lavá-las, mostrando-se também como inadequadas às particularidades geográficas de algumas propriedades rurais, cujo acesso é "ladeiroso" (Agricultor, Chã Grande, 58 anos).

Há uma preferência pelas sacolas plásticas ou "bolsas", na expressão do grupo, na medida em que permitem mais facilmente a sua condução pelos sítios, além de representarem um preço mais acessível. Tal afirmação é também constatada por Alves et al. (2013), para os quais a rejeição pelo uso destas caixas plásticas só será alterada com a adoção de estratégias que melhorem o sistema de cultivo nos sítios dos agricultores. Para Cunha (2013), normas desta natureza estão relacionadas à concepção, por parte dos coordenadores, de que as
Centrais seriam capazes de fortalecer a produção familiar focando em dimensões estritamente econômicas, sem considerar o conhecimento tácito dos agricultores sobre o mercado. Nesse sentido, pautam-se na possibilidade de modernizar as técnicas de produção e embalagem e gerenciar a logística, com vistas ao prolongamento da escala de abastecimento. Desse modo, negligencia-se os aspectos dos territórios e da cultura local, o que, em certa medida, caracteriza a ineficiência das Centrais em implantar programas de apoio à agricultura familiar (Cunha, 2013).

Em alguns casos, o suporte fornecido pelas associações e cooperativas, em termos de acesso às embalagens e, especialmente, a um sistema de transporte, se reveste de particular importância para a inclusão de agricultores menos capitalizados nesses circuitos. É o que se observa, por exemplo, com o caso da Cooperativa de Desenvolvimento da Agricultura Familiar do estado de Pernambuco (Coopafa), de Camocim de São Félix, que agrega 280 cooperados de nove municípios do estado ${ }^{8}$, transportando seus produtos para o galpão. A participação dessa cooperativa na Cecaf assegura a comercialização de $50 \%$ dos produtos dos seus associados. Tal cenário reforça a ideia da importância da cooperativa enquanto instrumento de potencialização da agricultura familiar, minimizando, assim, os seus riscos de exclusão, como já comentado por Pires $(2004 ; 2006)$.

Ainda assim, é importante sublinhar que a presença de associações e de cooperativas no galpão da agricultura familiar é pouco expressiva, contrariando o papel de destaque que essas entidades deveriam desempenhar no âmbito do projeto de criação da Cecaf. Sob as mais diversas alegações dos entrevistados, constata-se que as cooperativas agrícolas foram sucessivamente se desvinculando do galpão: "Na inauguração do galpão tinha cooperativa, tava lá o standezinho. Mas a coisa era muito teórica. Eu atribuo o insucesso à falta de estrutura da produção, de transporte, reforma agrária, de tudo, toda essa logística que faltava a eles" (Gerente do Ceasa-PE/O.S.). Atribui-se também ao fato de que inexistem na Cecaf, condições que permitam certas formalidades contratuais, como a emissão de notas fiscais e de mecanismos formais de divulgação dos produtos. Um dos entrevistados admitiu que a ideia de instauração de um balcão de negócios, como pensada

8 Corresponde aos municípios de Bonito, Barra de Guabiraba, Sairé, Belém de Maria, Camocim de São Feliz, Bezerros, Joaquim do Monte, Orocó e Cabrobó. 
inicialmente, mas jamais executada, poderia ter atraído maior participação das cooperativas (Gestor do MDA). Apesar das dificuldades expostas pelos agricultores, muitas das quais foram igualmente reconhecidas pelos gestores, há um reconhecimento, por parte destes últimos, de que o grande mérito na implementação da Cecaf consistiu na conquista de um espaço exclusivo para a agricultura familiar, sem o qual a inserção da agricultura familiar no Ceasa-PE/O.S. dificilmente aconteceria.

\subsection{A ocupação rotativa da pedra}

A "pedra," como habitualmente é conhecida, designa o espaço, no ambiente interno do galpão, onde os feirantes fixam suas bancadas, depositam e expõem as mercadorias. Não sem razão, costuma-se dizer que a participação na Cecaf depende da possibilidade de ocupação de uma pedra. Ainda que associada a um registro nominal, a forma de ocupação das pedras foi definida na fase da existência do comitê gestor, com base no uso rotativo e compartilhado, livre de formalização por meio de contrato. Tais procedimentos se diferem do que habitualmente vem sendo realizado em outros galpões do Ceasa-PE/O.S., nos quais os comerciantes ocupam estes espaços, via aluguel mensal.

No caso da Cecaf, estipulou-se o pagamento de uma taxa pelo uso diário, no valor de R\$ 11,00 por pedra, ou $R \$ 7,00$ para os agricultores portadores da Declaração de Aptidão ao Pronaf $\left(\mathrm{DAP}^{9}\right)$. O que, no caso da nossa amostra, limita-se a um grupo de apenas quatro agricultores, isto é, $12 \%$ do total da amostra. De acordo com os entrevistados, o pagamento diário das pedras podia resultar em custos mais elevados do que os aluguéis pagos em outros galpões, $\mathrm{O}$ discurso de um feirante é elucidativo nesse sentido, ao afirmar: “Eu pago R\$11 da pedra, são duas todo dia, faz a conta aí, vem um comerciante e paga nem a metade disso no mês... Isso tá certo?" (Agricultor, Brejo da Madre de Deus, 59 anos). A respeito dessas inquietações, um dos gestores assim se manifestou: "é uma questão de receita, e o Ceasa não pode abdicar porque ele vive em função disso" (Gerente do Ceasa-PE/O.S), indicando que o Ceasa-PE depende financeiramente do recolhimento destas $\operatorname{taxas}^{10} \mathrm{e}$ que a redução ou isenção não faz, portanto, parte dos planos da entidade.

\footnotetext{
9 Documento de identificação do agricultor familiar para acesso à políticas públicas (BRASIL, 1996).

10 Previsto pelo plano de trabalho de 2015/2016 do Ceasa-PE/O.S.
}

O uso rotativo das pedras em turnos e por ocupantes diferentes permite maior circulação de atores pela Cecaf. O que significa afirmar que, uma mesma pedra, ainda que vinculada a um único registro, pode ser usada por mais de um feirante, dificultando, assim, o controle minucioso sobre os usuários do galpão. O uso rotativo é criticado pelos usuários, por impedir o acondicionamento permanente dos produtos, como revelado numa entrevista: "não posso deixar minha mercadoria aqui, porque amanhã, como eu não venho, já tem outra pessoa aqui" (Agricultor, Vitória de Santo Antão, 46 anos). Apesar das limitações da pedra, esse sistema ainda representa uma das poucas condições de infraestrutura oferecidas pelas Ceasas para o produtor, como ressalta Cunha (2013).

As condições desfavoráveis de comercialização mencionadas pelos usuários não têm evitado uma disputa permanente das áreas do galpão, nem a sua superlotação. Pelo contrário, a superlotação do galpão tem gerado disputas para além dos espaços das pedras, invadindo os corredores e a plataforma de descarregamento de mercadorias. Para o gerente da Cecaf, a superlotação se dá por conta da gratuidade de acesso ao Ceasa-PE. Por isso, segundo ele, muitos desses feirantes "entram e não têm onde botar a mercadoria" (Gerente do Ceasa -PE/O.S), fazendo com que se instalem de forma precária, nos raros espaços ainda disponíveis. Vale ressaltar que o uso das ruas de acesso à Cecaf não deriva, necessariamente, da ausência de pedras disponíveis, podendo indicar a opção dos feirantes em não arcar com os custos das pedras e de poder atrair os clientes antes de chegarem ao galpão.

Além da superlotação, constata-se uma concentração do uso das pedras e do acesso às plataformas de descarregamento nas mãos de comerciantes mais capitalizados, gerando certo descontentamento por parte dos agricultores, que chegam a admitir que "hoje esse galpão é privado. O atravessador tem quatro, cinco áreas" (Agricultor, Chã Grande, 55 anos). Casos de favorecimento de pedras também vêm sendo constatados ao longo do tempo, decorrentes de procedimentos inadequados que remontam à implementação do projeto ${ }^{11}$. Como forma

11 Segundo Cunha (2006), faz parte do caráter público / privado do gerenciamento das Ceasas a concessão, por parte do corpo institucional, de privilégios aos comerciantes, o que culmina na desigualdade de acesso aos espaços de comercialização e na apropriação privada dos projetos públicos. A participação efetiva dos agricultores esbarra nas práticas consolidadas pela "força institucional e paralegal dos intermediários" (CUNHA, 2013. p 10). 
de minimizar as distorções em torno da utilização dos espaços, algumas medidas vêm sendo adotadas pela atual gestão, desde 2015, tais como: a instalação de uma tenda anexada à Cecaf, a flexibilização da setorização de produtos e a permissão da comercialização sobre rodas nos pátios de descarregamento da Cecaf. Tais medidas, ainda que tenham resolvido algumas situações emergenciais, ainda são consideradas insuficientes, dada a gravidade de algumas situações que definem o cenário cotidiano do galpão.

\subsection{O abastecimento agrícola da Cecaf}

Os agricultores comerciantes estão predominantemente envolvidos com a comercialização de acelga, alecrim, arruda, agrião, brócolis, couve folha, fava e batata-doce. A diversidade de produtos ofertados segue um padrão de divisão estabelecido pelo Ceasa-PE, que põe, de um lado, as folhosas e, de outro, os legumes, com menor concentração de frutas. Além disso, prevalece, dentre esses agricultores, uma preocupação permanente com a organização e com a boa aparência dos hortifrútis expostos no interior do galpão, gerando uma demanda de trabalho no âmbito da conservação da aparência fresca dos produtos, seja na exclusão dos produtos imperfeitos e impróprios ao consumo, seja no desfolhamento dos repolhos, por exemplo. Há também pessoas voltadas à confecção de molhos, com o retalhamento das folhosas destinadas à comercialização em varejo. Em $56 \%$ dos casos, esse trabalho não representa um custo adicional para os agricultores comerciantes, considerando que, muitos deles, fazem parte do grupo familiar. Para os demais $24 \%$ dos entrevistados, este trabalho é exercido por terceiros, e para $20 \%$ há uma combinação entre pessoas da família e empregados informalmente contratados.

As lavouras dos agricultores comerciantes são direcionadas tanto para o autoconsumo - chamando a atenção para o que a literatura denomina de sistema tradicional de produção camponês (Heredia, 1979; Garcia Junior, 1989; Wanderley, 1999) - como para contemplar os produtos que estão setorizados na Cecaf. "Planto coentro, feijão de sopa, macaxeira e milho, pro sustento de casa. E tem que plantar chuchu que a gente vive dele," comenta, nesse sentido, um agricultor (Agricultor, Chã Grande, 47 anos). Ainda assim, como admitem alguns entrevistados, a produção própria é insuficiente para o abastecimento da Cecaf, fazendo com que dependam também de fornecedores, muitos dos quais são contatados no trajeto até o entreposto. Dois motivos contribuem para isso: a sazonalidade da produção, na qual "plantio nenhum tem direto. Ninguém tem produção de inverno a verão" (Entrevistado 25, Passira, 48 anos), e a impossibilidade de produção em alta escala para atender às demandas de comercialização do Ceasa.

A diversidade produtiva típica da agricultura familiar constituía um dado de destaque no âmbito do projeto de implementação da Cecaf. Previa-se a possibilidade de esse galpão funcionar de forma semelhante às feiras livres, privilegiando-se a diversidade dos produtos ofertados. No entanto, com o processo de setorização dos produtos do Ceasa-PE/O.S., este projeto fora inviabilizado. No caso da Cecaf, esta setorização tanto tem sido apontada como uma forma de organização e disciplinamento deste mercado, como um elemento de engessamento dos agricultores. Nesse último caso, por exemplo, como observado por um dos agricultores comerciantes: "Eu quero vender tomate, outras coisas que eu planto, mas não posso porque o Ceasa não deixa, porque o galpão do tomate é outro" (Agricultor, Brejo da Madre de Deus, 59 anos). Ao que um segundo complementa: "Eu plantava graviola, aí botaram a graviola no galpão da fruta, aí eu vou me dividir em dois?" (Agricultor, Chã Grande, 50 anos). De todo modo, o processo de setorização instituído pelo Ceasa-PE tende a contrariar o sistema de plantio pautado na policultura que define a dinâmica produtiva da agricultura familiar.

Tal cenário nos remete à discussão de Belik (2015) em torno da inadequação das políticas implementadas pelas centrais, tanto em termos de uma possível consolidação de uma plataforma logística para a agricultura familiar como em termos de aperfeiçoamento do sistema de abastecimento brasileiro. Trata-se, pois, como admite, das "irracionalidades" contidas nas ações de coordenação destes espaços (Belik, 2015). O autor dá particular atenção aos grandes deslocamentos das mercadorias, muitas das quais com mais de $600 \mathrm{~km}$ de distância, representando fraca articulação com a produção local, como já sublinhado por Cunha \& Belik (2012).

\subsection{Definição de preços}

No tocante ao mecanismo de definição de preços das mercadorias, os agricultores comerciantes se pautam, em grande medida, na observação do volume de oferta dos concorrentes. Além disso, os agricultores costumam praticar uma consulta prévia aos fornecedores, para melhor se inteirarem sobre o volume de mercadorias 
322 Agricultura familiar e mercados atacadistas: dinâmicas sociais da Central de Comercialização da Agricultura Familiar (Cecaf/Ceasa) em Recife - Pernambuco

que será enviado ao galpão, evitando, assim, maiores surpresas quanto à oferta de uma quantidade excessiva de um dado produto, como ilustrado pela fala do entrevistado: "Eu ligo e pergunto antes mesmo de chegar aqui, pra saber quanto que vai chegar. Aí já vou botando o preço no que eu tenho" (Agricultor, Chã de Alegria, 56 anos). A definição dos preços dos produtos também pode ser estabelecida a partir da visualização do volume de mercadorias nas carrocerias, antes mesmo do descarregamento dos caminhões. Assim, como observa um feirante, "se chegar muita mercadoria, vai ter que vender barato, se chegar pouca, a gente vai vender mais caro" (Agricultor, Catende, 52 anos).

Ainda que o movimento de clientes e a concorrência entre os feirantes sejam mais intensos no período da manhã, implicando em oferta de preços capaz de atrair a clientela, é no período da tarde, quando a oferta e a procura tornam-se mais escassas, que os preços recuam. Como admite um entrevistado, o comércio da Cecaf se assemelha à "uma maré: de manhã tá cheia e de tarde tá seco" (Agricultor, São Joaquim do Monte, 57 anos). Vale ressaltar que a flutuação dos preços também está relacionada ao volume de oferta de um dado produto, o que, por sua vez, também se relaciona à sazonalidade dos cultivos e à ocorrência ou não de chuvas nas regiões produtivas. Finalmente, as mercadorias que sobram ou "boiam", na expressão local, fazem parte do cotidiano daqueles agricultores que comercializam produtos de alta perecibilidade, a exemplo do coentro e de outras folhosas. Nesse contexto, quando o coentro "boia" acaba sendo descartado, tendo em vista que "é um produto melindroso, você arranca num dia, no mesmo dia se perde" (Agricultor, Chã de Alegria, 56 anos).

Os mecanismos elencados indicam que os comportamentos, julgamentos e normas dos agricultores comerciantes estão estritamente ligados às circunstâncias locais, influenciados pela constante flutuação do volume de mercadoria. Constata-se, assim, que é no nível local que os atores estabelecem as normativas nos processos presentes vividos. Assim, a prática de determinar o preço da mercadoria se revela um exercício de aprendizado permanente permitido pelas regras de mercado e pelas interações sociais entre os diversos atores envolvidos. O reconhecimento destas "expertises" reitera a tese de Cunha (2006) de que há um conhecimento tácito sobre o funcionamento do mercado, que está pouco sistematizado gerencialmente pelas Ceasas, mas que, em contrapartida, é relevante para formulação de ferramentas gerenciais.

\section{Considerações finais}

Criada com o objetivo de apoiar a agricultura familiar, por meio dos agricultores beneficiados pelo Pronaf, o projeto da Cecaf estruturou-se em torno da possibilidade de um processo formativo permanente dos usuários desse galpão e de um forte apelo ao associativismo. Entretanto, nenhum desses requisitos fora plenamente concretizado. Além do número inexpressivo de beneficiários do Pronaf, o processo de formação daqueles participantes resumiuse a algumas escassas reuniões, sob a coordenação de um comitê gestor de Assistência Técnica e Extensão Rural (Ater), do estado de Pernambuco. Ademais, a participação de associações e cooperativas também fora incipiente. De qualquer forma, a inexpressividade da presença de beneficiários do Pronaf não impediu, entretanto, que a Cecaf fosse popularmente conhecida como galpão do "Pronaf".

O que se observou foi que, desde o início, a Cecaf precisou reformular o seu público-alvo, passando a incorporar outros atores sociais, muitos dos quais já participantes do cotidiano do Ceasa-PE, praticando a comercialização em outros galpões. O que indica, por conseguinte, que a Cecaf não representa, para muitos dos seus usuários, a primeira experiência no âmbito do Ceasa. Representa, sim, a continuidade de um percurso definido ao longo do tempo pelo próprio Ceasa-PE, na tentativa de reorganização dos seus galpões, por tipos específicos de produtos. Um processo que se associa, desse modo, aos permanentes "giros" vivenciados pelos agricultores, a quem não cabe grandes possibilidades de escolha, ou de consultas.

Atualmente, constata-se, no galpão, um público de outras categorias de trabalhadores formais e informais, além dos tradicionais agricultores produtores, agricultores comerciantes e comerciantes parceiros, sinalizando uma nova divisão social do trabalho. Nesta pesquisa, foram privilegiados os agricultores comerciantes por demonstrarem uma participação mais ativa na dinâmica do galpão. Por meio deles, foi possível constatar que suas experiências de comercialização definem um modo de vida e de trabalho alimentado por um aprendizado permanente, a partir da formulação de estratégias de compra e venda dos produtos e das interações sociais com fornecedores e clientes. Manter uma ampla rede de contatos, saber lidar com a definição de preços dos produtos e com as normas formais e informais de 
utilização das pedras são algumas das exigências que definem o modus operandi desses atores.

A participação na Cecaf também exige destes agricultores a incumbência de custos permanentes, seja com o pagamento da taxa de romaneio e das pedras, seja com as habituais despesas para o transporte das mercadorias e, ainda, com a eventual necessidade de contratação de empregados para trabalhos pontuais no interior do galpão. Soma-se a esses custos a necessidade de aquisição de produtos junto a fornecedores. Os agricultores necessitam, nesse sentido, complementar a gama de produtos por eles ofertados, em razão de o volume desta produção ser insuficiente para atender às escalas de abastecimento do galpão, sobretudo em função da setorização promovida pelo Ceasa-PE, que organiza os galpões por tipos de produtos. Assim, a incompatibilidade da setorização com a dinâmica de cultivo da agricultura familiar foi um dado que se destacou nessa pesquisa. Isso nos permite afirmar que a setorização tende a inibir o processo de diversificação da produção típico da dinâmica da agricultura familiar, passando a estimular a especialização, como forma de adequação às condições e aos mecanismos externamente ditados. $\mathrm{O}$ fato é que o conhecimento tácito dos agricultores não está sendo incluído na formulação das estratégias gerenciais da Cecaf.

Foi também observado que a necessidade de uma grande dedicação dos agricultores ao trabalho na Cecaf, requerida pela intensa rotina de comercialização, tem levado muitos deles à desativação da produção, rompendo, assim, com as bases da agricultura familiar. Em alguns casos, inclusive, tem dificultado a sua permanência no campo. Isso nos autoriza a sinalizar para uma certa tendência de mudança de categoria de usuário do galpão: de agricultores comerciantes para exclusivamente comerciantes. Esse é um dado particularmente relevante quando se considera que o objetivo de criação da Cecaf estava na possibilidade de atender às necessidades de escoamento da produção da agricultura familiar, contribuindo, assim, para a reprodução social dessa categoria, a partir da geração de renda e fixação das populações no campo.

A mudança da natureza dessa ocupação denuncia o desvirtuamento dos seus objetivos, comprometendo a função social à qual a Cecaf esteve originalmente vinculada, levando, assim, à descaracterização do galpão. O que, apesar disso, não implica desconsiderar a expressiva presença de agricultores familiares entre os usuários do galpão. Para esses, as condições de autoabastecimento, a partir da diversidade de cultivos, são um dado que se faz presente nos discursos, ainda que se constate a predominância de cultivos comerciais associados às demandas instituídas na Cecaf.

Tais demandas incluem, pela sua natureza, a tarefa de escoar, depositar e oferecer as mercadorias no galpão, a presença de trabalhadores com funções específicas, seja os "siris," os separadores de produtos de segunda linha, ou os desfolhadores de repolhos, coentros e folhosas.

De todo modo, a racionalidade capitalista presente nas logísticas instituídas pela Cecaf não pode prescindir de outra racionalidade, aquela que move a dinâmica da agricultura familiar. Uma racionalidade pautada na diversificação da produção, na cooperação da família, que planta no roçado e que cuida da comercialização na Cecaf, que seleciona o produto e que lhe garante também melhor aparência, ao desfolhar os repolhos, por exemplo. A conservação da identidade da Cecaf, enquanto Central de Comercialização da Agricultura Familiar, bem como a sua preservação no tempo, passam, necessariamente, pela problematização dessas questões.

Foi possível constatar que, enquanto a venda em atacado vem se caracterizando como reprodução da tradicional grande escala de distribuição, voltada para a especialização dos tipos de produtos setorizados na Cecaf, a venda em forma de varejo, por outro lado, tem permitido o contato direto entre produtor e consumidor, a inserção de trabalhadores desempregados da cidade e o estabelecimento da agricultura urbana no entorno do Ceasa-PE. Isso implica dizer que essas logísticas têm gerado oportunidades de trabalho, ainda que em condições informais e em certa medida, precárias. A presença dos "siris" na disputa dos espaços da Cecaf é emblemática nesse sentido.

Também se constatou que, embora o uso rotativo e compartilhado das pedras tenha sido estipulado desde as primeiras reuniões pelo comitê gestor, os diversos atores se encontram em desiguais condições para acessá-las, privilegiando aqueles com maior influência e/ ou capitalização, o que gera concentração de poder e de oportunidade no uso do espaço. Tal fato tem sido uma fonte permanente de descontentamento e de conflitos, exigindo que o Ceasa-PE passasse a disponibilizar áreas externas ao galpão, como forma de minimizar as tensões em torno da demanda por espaços. Associada à superlotação dos espaços, a dinâmica de comercialização instituída no galpão tem se caracterizado por reproduzir 

Agricultura familiar e mercados atacadistas: dinâmicas sociais da Central de Comercialização da Agricultura Familiar (Cecaf/Ceasa) em Recife - Pernambuco

mecanismos de dependência e subalternidade entre comerciantes mais capitalizados na sua relação com os demais participantes.

A informalidade que rege a dinâmica dessa comercialização não tem se constituído como um fator favorável à presença das cooperativas. Mesmo assim, a sua participação, ainda que muito incipiente no conjunto das operações e praticamente restrita ao abastecimento deste galpão, tem possibilitado a participação de agricultores familiares, que, de outra forma, dificilmente teriam condições de participar deste mercado.

Finalmente, a dinâmica social de funcionamento da Cecaf expõe as incongruências das normas instituídas pelo sistema Ceasa-PE, que, além de não estarem compatíveis com as necessidades da agricultura familiar, tem posto em xeque algumas questões relacionadas à sua tradição. A questão que ora se impõe é a seguinte: Quais as implicações no futuro da Cecaf quando são consideradas: a) a ampliação do público-alvo para outros usuários, além dos agricultores familiares; b) a inibição da diversificação da produção, em função de um processo crescente de setorização; c) a ampliação do tempo de permanência dos agricultores nos centros urbanos e a concomitante secundarização da atividade agrícola e d) a pouca ou ausente admissão do conhecimento tácito sobre o funcionamento do mercado para determinação das operações logísticas.

Muito possivelmente, a resposta a essa e a outras questões exige permanente aprofundamento nas análises em torno das dinâmicas de abastecimento instituídas pelas categorias sociais de agricultores inseridos na comercialização da Cecaf no âmbito do Ceasa-PE. A análise de outras experiências das Ceasas brasileiras possivelmente ampliaria a compreensão sobre as dinâmicas sociais e produtivas que caracterizam as condições de participação da agricultura familiar nesses espaços.

\section{Referências}

Alves, P. D. E., Vital, T. W., Bezerra, A. C., Silva, R. M. F., Andrade, M. A. T. B., Bovet, M. B., \& Musser, R. S. (2013, dezembro 09-13). Desenvolvimento de um Sistema Central de Embalagens para os produtos comercializados no Centro de abastecimento alimentar de Pernambuco (CEASA-PE/O.S.)-ETAPA III. In Anais do JEPEX (pp.1-3). Recife: UFRPE.
Belik, W. (2015). A Heterogeneidade e suas Implicações para as Políticas Públicas no Rural Brasileiro. Revista de Economia e Sociologia Rural, 53(1), 9-30.

Belik, W., \& Cunha, A. R. A. (2015). Abastecimento no Brasil: o desafio de alimentar as cidades e promover o Desenvolvimento Rural, 2015. In C. Grisa, \& S. Schneider (Eds.), Políticas públicas de desenvolvimento rural no Brasil. Porto Alegre: Ed. UFRGS.

Belik, W., \& Maluf, R. S. (2000). Abastecimento e segurança alimentar: os limites da liberalização. Campinas: Ed. UNICAMP.

Bonanno, A. (2003). La globalización agro-alimentaria: sus características y perspectivas futuras. Revista Sociologias, 5(10), (190-218).

Bonanno, A. (2016). Tierra, capital y trabajo en el proceso de reestructuración neoliberal de la agricultura. Madri: Fundación de Estudios Rurales Anuario.

Brasil. (1996). Ministério do Desenvolvimento Agrário. Manual operacional do PRONAF. Brasília: PRONAF.

Brasil. Ministério da Agricultura. (2000). Lei no 9.972, de 25 de maio de 2000. Institui a classificação de produtos vegetais, subprodutos e resíduos de valor econômico e dá outras providências. Diário Oficial [da] República Federativa do Brasil, Brasília.

Cavalcanti, J. S. B. (2004). Globalização e ruralidade. In M. N. B. Wanderley (Org.), Globalização e desenvolvimento sustentável: dinâmicas sociais rurais no Nordeste brasileiro. São Paulo: Polis.

CEASA-PE O/S. (2008). Relatório técnico da implantação da Central de Comercialização da Agricultura familiar CECAF. Recife: CEASA, Departamento Técnico - DETEC.

CEASA-PE O/S. (2016). Plano de Trabalho-Departamento Técnico-DETEC. Recife: CEASA. Recuperado de www. ceasape.org.br/.../planodeacao/15015092415393planodetrabalho20162016.pdf

CEASA-PE O/S. (2017, junho 07). CEASA em números. Recife: CEASA.

Cimadevilla, G., \& Kenbel, C. (2014). La maquina de circular cultura. Revista ALAIC.

Cunha, A. R. A. (2006). Dimensões estratégicas e dilemas das Centrais de Abastecimento no Brasil. Revista de Política Agrícola, 15(4), 37-46.

Cunha, A. R. A. (2013, julho 21-24). Qual a ruralidade das Ceasas. Evidências sobre a inserção da agricultura familiar nas Centrais de abastecimento brasileiras. In Anais 51ํㅡㄹ Encontro da SOBER (pp. 1-21). Belém: SOBER.

Cunha, A. R. A., \& Belik, W. (2012). Entre o declínio e a reinvenção: atualidade das funções do sistema público atacadista de alimentos no Brasil. Revista de Economia e Sociologia Rural, 50(3), 435-454. 
Cunha, A. R. A., \& Campos, J. B. (2008). O sistema de abastecimento atacadista no Brasil: uma rede complexa de logística. Belo Horizonte.

Faulin, E. J., \& Azevedo, P. F. (2003). Distribuição de hortaliças na agricultura familiar: uma análise das transações. Informações Econômicas, 33(11), 24-37.

Fávero, L. A. (2005). Novas formas de coordenação das atividades de abastecimento nos mercados atacadistas de frutas e hortaliças da América Latina. In Anais do Congresso da SOBER. Ribeirão Preto: SOBER.

Ferreira, R. J. (2013). Agricultura urbana e periurbana e políticas públicas: contribuição à discussão do tema a partir de uma análise espacial em Recife e Vitória de Santo Antão/ PE (Tese de doutorado). Universidade Federal de Pernambuco, Recife.

Garcia Junior, A. (1989). O Sul: caminho do roçado Estratégias de reprodução camponesa e transformação social. São Paulo: Editora Marco Zero.

Grisa, C., \& Schneider, S. (2015). Três gerações de políticas públicas para a agricultura familiar e formas de interação entre sociedade e Estado no Brasil. Revista de Economia e Sociologia Rural, 52(Supl. 1), S125-S146.

Heredia, B. M. A. (1979). Morada da vida - Trabalho familiar de pequenos produtores do nordeste do Brasil. Rio de Janeiro: Paz e Terra.

Maluf, R. (2004). Mercados agroalimentares e a agricultura familiar no Brasil: agregação de valor, cadeias integradas e circuitos regionais. Ensaios FEE, 25(1), 299-322.

Mourão, I. R. (2007). Diretrizes de engenharia e arquitetura para equipamentos de comercialização de produtos hortícolas no atacado. Brasília: Conab.

Mourão, I. R. (2008). Manual I: breve história do sistema de CEASAs no Brasil (1960 a 2007) (Relatório técnico).

Mourão, I. R., \& Magalhães, J. S. B. (2009). Breve história do mercado atacadista de hortigranjeiros no Brasil. Revista de Administração Municipal do Intituto Brasileiro de Administração Municipal, 9:1-38.

Nascimento, W. G. (2008). As centrais públicas de abastecimento no contexto da globalização dos alimentos - Entre as mudanças na forma de atuação do estado e o fortalecimento dos grandes distribuidores: o caso do CEASA-PE/O.S. (Dissertação de mestrado). Universidade Federal de Pernambuco, Recife.

Niederle, P. A., Almeida, L., \& Vezzani, F. M. (2013). Agroecologia: práticas, mercados e políticas para uma nova agricultura. Curitiba: Kairós.

Pires, M. L. S. (2004). O cooperativismo agrícola em questão - A trama das relações entre projeto e prática em cooperativas do nordeste do Brasil e do leste do Canadá (Québec). Recife: Massangana.

Pires, M. L. S. (2006). O cooperativismo para além do mercado e do estado: a solidariedade em debate. In M. S. T. Santos, \& A. B. F. B. Callou (Orgs.). Associativismo e desenvolvimento local. Recife: Bagaço.

Ploeg, J. D. V. D. (2008). Camponeses e impérios alimentares: lutas por autonomia e sustentabilidade na era da globalização. Porto Alegre: Editora UFRGS.

Sabourin, E. (2009). Camponeses do Brasil: entre a troca mercantil e a reciprocidade. Rio de Janeiro: Garamond.

Santos, M. (2008). O espaço dividido: os dois circuitos da economia urbana dos países subdesenvolvidos. São Paulo: Edusp.

Souza-Esquerdo, V. F., \& Bergamasco, S. M. P. P. (2014) Análise sobre o acesso aos programas de políticas públicas da agricultura familiar nos municípios do circuito das frutas (SP). Revista de Economia e Sociologia Rural, 52(Supl. 1), 205-222.

Teixeira, C. T. M., \& Pires, M. L. L. S. (2017). Análise da relação entre produção agroecológica, resiliência e reprodução social da agricultura familiar no Sertão do Araripe. Revista de Economia e Sociologia Rural, 55(1), 47-64.

Wanderley, M. N. B. (1999). Raízes históricas do campesinato brasileiro. In J. C. Tedesco (Org.), Agricultura familiar: realidades e perspectivas. Passo Fundo: EDIUPF.

Wegner, R. C., \& Belik, W. (2012). Distribuição de hortifrúti no Brasil: papel das Centrais de Abastecimento e dos supermercados. Cuadernos de Desarrollo Rural. International Journal of Rural Development, 9(69), 195-220. 